\title{
Identification and Reconsidering Phylogeny of Some Aphid Species, (Hemiptera: Aphididae), Based on Molecular DNA Markers Using ISSRs-PCR Technique
}

\author{
Ibrahim A Adss', Reda M Tabikha ${ }^{2 *}$ \\ 1- Genetic Department, Faculty of Agriculture, Damanhour University, Damanhour, Egypt \\ 2- Plant Protection Department, Faculty of Agriculture, Damanhour University, Damanhour, Egypt \\ * Corresponding author: Reda.Tabikha@agr.dmu.edu.eg
}

DOI:10.21608/ajs.2021.94272.1414

Received 5 September, 2021 ; Accepted 18 December, 2021

\section{Keywords:}

Aphid,

DNA,

ISSRs,

Phylogeny,

Molecular,

Egypt

\begin{abstract}
Aphids are considered as most economically importance and worldwide insect pests. Successful pest management systems are based on accurate and rapid pests' species identification. Traditional morphological identification of closed aphid species may be considered as inaccurate taxonomic process. For overcoming disadvantages of traditional morphological identification, molecular techniques, related to DNA markers and based on polymerase chain reaction (PCR), were approached by using nine ISSRs primers to identify and diagnose fifteen common aphid species that disperse in Egyptian agro-ecosystem. The examined ISSRs primers could successfully discriminate the tested aphid species that reflected $61.39 \%$ polymorphism among them. Moreover, four banding patterns were considered as unique bands which could characterize three aphid species (Aphis gossypii, Aphis nerii and Myzus persicae). Highest genetic homology (84.9\%) was observed between species Rhopalosipum padi and Schizaphis graminum. In additions, each of A. gossypii and Aphis citricola were also genetically homologous species. In contrast, species Aphis craccivora and M. persicae were analogous genetically with low similarity percentile (59.8\%). High genetic divergence was observed also between $A$. nerii and $M$. persicae. Two alternative molecular branching taxonomic keys were proposed by subjecting five highest polymorphic ISSRs primers and 29 banding patterns with different molecular sizes.
\end{abstract}

\section{Introduction}

Aphids (Hemiptera: Sternorrhyncha: Aphididae) are considered the most economical importance and worldwide insect pests (Emden and Harrington 2007), which are more common in temperate zones (Blackman and Eastop 2000). They are invasive pests, that threaten agricultural production and cause severe crop losses reach 7080\% (Capinera 2002, Holman 2008, Kinyanjui et al 2016). Direct feeding of aphid on plant sap can cause not only depriving essential nutrients of host plant, but also transmitting $30 \%$ of plant viral diseases, and injecting toxic salivary secretions to host plants (Blackman and Eastop 1994 and 2000, Brault et al 2010). In addition, sooty molds that results in honey dew secretion can also cause effective depleting in photosynthesis of host plants and reducing quality and then marketability of crops (Worf et al 1995).

Family Aphididae is consisting of more than 4000 species. Aphidinae is the largest subfamily of Aphididae that consists of three major Tribes. Macrosiphini is considered as the largest tribe of Aphidinae that consists of more than 2000 species, followed by 
Aphidini with 750 species then Pterocommatini with 50 species (von Dohlen et al 2006, von Dohlen 2009). Aphidina and Rhopalosiphina are only subtribes of Aphidini.

Successful systems of plants quarantine and pests management are based on accurate and rapid pests' species identification (Lozier et al 2008, Miller and Foottit 2009). Classification of aphid at various levels has been conducting by using morphological characters, life cycles and host-plants associations (Blackman and Eastop 1994, Kim et al 2011). Although absence of morphological characteristic keys or existence of polymorphic, cryptic, small, immature, and damaged specimens complicated the determination process of aphid species (Armstrong and Ball 2005, Lee et al 2011, Kinyanjui et al 2016), morphological traits were used to identify numerous aphid species (Emden and Harrington 2007). Furthermore, morphological determination of aphid species required taxonomists with specific knowledge, skills and training which may be acquire in many years, thus related aphid species determination, based on traditional morphological characters, may be timeconsuming and considered as an inaccurate taxonomic process (Coeur d'acier et al 2014).

For overcoming the limitation of traditional morphological identification, molecular techniques, related to DNA markers and based on amplification of specific regions of the genome by using polymerase chain reaction (PCR) techniques, were approached (Mullis and Faloona 1987) and then organisms as cryptic invertebrates or immature stages as egg could be identified $(\mathrm{Ca}-$ rew et al 2003 and 2005, Hebert et al 2004). Thus, McNeely et al (2001) reported that using molecular identification system may be assist in identification procedure of difficult or indistinguishable specimens. The most frequently used molecular markers "allozymes, random amplified polymorphic DNA (RAPD), amplified fragment length polymorphism (AFLP), restriction fragment length polymorphism (RFLP), DNA microsatellite (SSR, STR), inter-simple sequence repeats (ISSRs), single nucleotide polymorphisms (SNPs), mitochondrial DNA (mtDNA) and barcoding" have been approached and reviewed to be applied in studying populations and genetic diversity of aphid species (Guo et al 2017).

RAPD-PCR, based on amplification of random regions of genome by using a single arbitrary tenmer primer that flank randomly with DNA, reveals successfully genetic polymorphisms among different insect species (Williams et al 1990). The diagnostic DNA markers, generated by RAPD-PCR, were used to identify different aphid species that belong to the genus Aphis (Amin et al 2008) and the Tribe Macrosiphini, in Egypt (Amin et al 2013). Furthermore, it was used to diagnose aphid geographical populations such as Rhopalosiphum padi in Egypt (Tabikha and Adss 2016). Using appropriate restriction enzymes to digest PCR product by RFLPPCR assists to determine numerous aphid species (Valenzuela et al 2007 and 2009, Kinyanjui et al 2016).

Finally, ISSRs may be reliable, polymorphic and unexpansive technique (Raina et al 2001), thus ISSRs have been used for studying taxonomic status of various animal populations. Moreover, Gui et al (2008) reported that ISSR is considered as specific technique to detect genetic variability among insects' species. Thus, it could successfully identify two aphid species "Pemphigus obesinymphae and Acyrthosiphon pisum" (Abbot 2001), characterize cereal aphid species (Helmi and Khafaga 2011), and differentiate geographical populations for each of Rhopalosiphum padi (Tabikha and Adss 2016) and S. graminum (Tabikha and Adss 2021) in Egypt. In addition, biotypes of insects such as Schizaphis graminum could be also differentiated by ISSRs (Weng et al 2007). The ISSRs were also subjected to study genetic diversity of Sogatella furcifera which considered as main species of plant hoppers (Liu et al 2010). Finally, it was employed to find diagnostic markers for fifteen leafhoppers species collected from different medicinal and aromatic plants in Egypt (Helmi et al 2016).

Thus, current research paper aims to pursue finding diagnostic DNA markers and studying genetic diversity of most common aphid species in Egypt based on ISSRs-PCR test. Furthermore, the obtained diagnostic DNA markers are also subjected to construct a molecular branching key that distinguishes the fifteen tested aphid species in Egypt.

\section{Materials and Methods}

\subsection{Specimens' preparation}

Molecular genetic analysis for fifteen of the most common and economic importance aphid species, classified in Tribes Macrosiphini and Aphidini, were conducted. Viviparous adults of the tested species were monitored on their host plants in different localities of Egypt and were collected and transferred to laboratory in glass jar supplemented with parts of host plant. Presented data in Table 1 summarize information of taxonomic status, locality, host plant and 


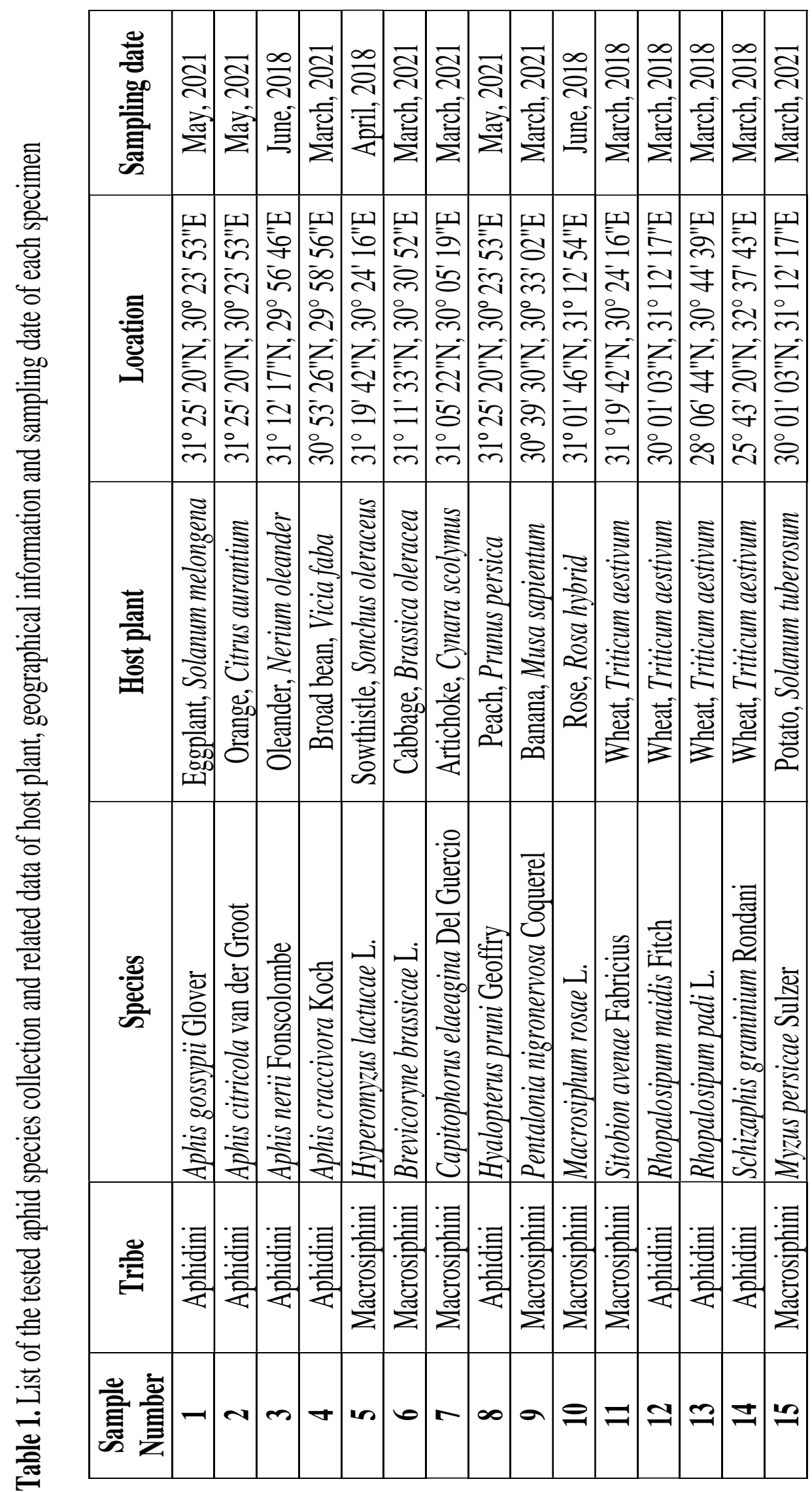


collection date that related to the tested aphid specimens. To confirm taxonomic status of each specimen, mounted alate or apterus forms of the tested aphid adults in swan's gum chloral media on glass slides (Blackman and Eastop 2000), were identified morphologically by using local taxonomic key of Habib and El-Kady (1961) or universal taxonomic key of Blackman and Eastop (1994) and (2000). Under laboratory conditions $\left(28 \pm 2^{\circ} \mathrm{C}, 65 \pm 5 \mathrm{RH}\right.$ and $\left.12: 12 \mathrm{~h}\right)$, healthy and young adult female from each tested aphid species were caged separately on its host plant to harvest its offsprings in age 5 days. The collected offsprings were preserved in Eppendorf tubes under $20^{\circ} \mathrm{C}$ for using later in molecular studies.

\subsection{DNA extraction}

Extracted genomic DNA of the fifteen preserved aphid specimens were subjected to polymerase chain reaction with nine ISSRs primers. Thus, 5-6 individuals of aphid adults were grinded to a fine powder, in Eppendorftubes under liquid nitrogen, the grinded material were transferred to tubes $(1.5 \mathrm{ml})$ then $750 \mu \mathrm{l}$ of extraction buffer "Acetyl Trimethyl Ammonium Bromide (CTAB)" were added as described procedure by Tabikha and Adss (2016). Quantity and quality of extracted DNA was determined by electrophoresis in agarose gel and spectrophotometry, that $5 \mu \mathrm{l}$ of extracted DNA with $10 \mu \mathrm{l}$ of loading buffer was mixed and electrophorized in Agarose gel 1.2\% with TBE buffer under 80 volts for $30 \mathrm{~min}$.

\subsection{ISSRs-PCR preparations and conditions}

To differentiate and fingerprint the tested aphid species, PCR was performed by using nine Inter Simple Sequence Repeats (ISSRs) primers with genomic DNA of the tested aphid species. The sequences of ISSRs primers are presented in Table 2. The polymerase chain reaction was run in final volume of $25 \mu \mathrm{L}$ that contained $2 \mu \mathrm{L}$ of ISSRs primer, $2 \mu \mathrm{L}$ DNA, $0.2 \mu 1$ Taq DNA polymerase (5U $\mu 1^{-1}$, Promega Germany), $2.5 \mu \mathrm{l} 4 \mathrm{mM}$ dNTPs, $2.5 \mu \mathrm{l} 10 \mathrm{x}$ buffer, and $2.5 \mu \mathrm{l} 50 \mathrm{mM}$ $\mathrm{MgCl}_{2}$.

The thermal conditions of PCR were adjusted to $94^{\circ} \mathrm{C}$ for $5 \mathrm{~min}$ for one cycle (initial denaturation), 40 cycles that each cycle includes denaturation at $94^{\circ} \mathrm{C}$ for $1 \mathrm{~min}$, annealing at $55^{\circ} \mathrm{C}$ (with ISSRs primers: UBC814, UBC818, UBC840 and UBC880 primers), $57^{\circ} \mathrm{C}$ (with ISSRs primers
UBC817, UBC826, UBC827 and UBC847 primers) or $60^{\circ} \mathrm{C}$ (with ISSRs primer: UBC812) for $75 \mathrm{sec}$. then extension at $72^{\circ} \mathrm{C}$ for $2 \mathrm{~min}$. The Final extension was adjusted on $72^{\circ} \mathrm{C}$ for $10 \mathrm{~min}$. The yield of PCR were electrophoresed in agarose gel $(1 \%)$ and TBE buffer under $120 \mathrm{~V}$ for 1.5 hours. Ethidium bromide solution was used to visualize DNA banding patterns of different specimens on agarose gel to be photographed later by using Bio-Rad Gel documentation system version 2000.

\subsection{DNA markers and phylogenetic relationships}

Bands variations among species with different ISSRs primers were recorded by Gene_Profiler_Eval computer program. To detect DNA markers of different species, generated banding patterns of the fifteen tested aphid species were valued 0 or 1 according to absence or presence of band, respectively. To construct molecular taxonomic key for the tested species, unique and polymorphic bands were detected and surveyed. The Phylogenetic relationship and genetic comparison among the fifteen aphid species were concerned by estimating Jaccard's similarity coefficient and using Multi-Variate Statisical Pakage (MVSP) Version 3.1. According to Sneath and Sokal (1973), the Unweighted Pair Group Method with Arithmetic Means (UPGMA) with estimated Jaccard's similarity coefficient were used to conduct cluster analysis of the data matrix.

\section{Results and Discussion}

\subsection{Banding patterns analysis}

Reaction of the nine ISSR primers with genomic DNA of the tested aphid species generated 101 banding patterns with molecular sizes ranged between 100 - 1100 bp Fig 1. Although 39 out of generated banding patterns are monomorphic, the all used ISSRs primers could successfully discriminate the tested aphid species that reflected $61.39 \%$ polymorphism among them. DNA fragment pattern analysis showed that 4 out of the polymorphic banding patterns are unique bands which could characterize three aphid species. Primer UBC814 generated the highest number of DNA fragments (168), on contrary primer UBC817 yielded the lowest number (84 fragments). Primer UBC847 could reflect highest polymorphism (100\%) among the examined aphid species. The tested ISSRs primers yielded lowest numbers of DNA band patterns (66 bands) in species A. nerii and Pentalonia nigronervosa while the highest ( 80 bands) was in species Capitophorus elaeagina. Despite, Primer of UBC812 produced 13 
Table 2. Sequences and annealing temperature of the examined ISSRs primers

\begin{tabular}{|c|c|c|}
\hline Codes of ISSRs Primers & $\begin{array}{c}\text { Sequencing of Nucleotide } \\
\mathbf{5}^{`}\end{array}$ & Annealing Temperature ${ }^{\mathbf{}} \mathbf{C}$ \\
\hline UBC-812 & GAGAGAGAGAGAGAGAA & 60 \\
\hline UBC-814 & CTCTCTCTCTCTCTCTCTA & 55 \\
\hline UBC-817 & CACACACACACACACAA & 57 \\
\hline UBC-818 & CACACACACACACACAG & 55 \\
\hline UBC-826 & ACACACACACACACACC & 57 \\
\hline UBC-827 & ACACACACACACACACG & 57 \\
\hline UBC-840 & GAGAGAGAGAGAGAGATT & 55 \\
\hline UBC-847 & CACACACACACACACAGC & 57 \\
\hline UBC-880 & GGAGAGGAGAGGAGA & 55 \\
\hline
\end{tabular}

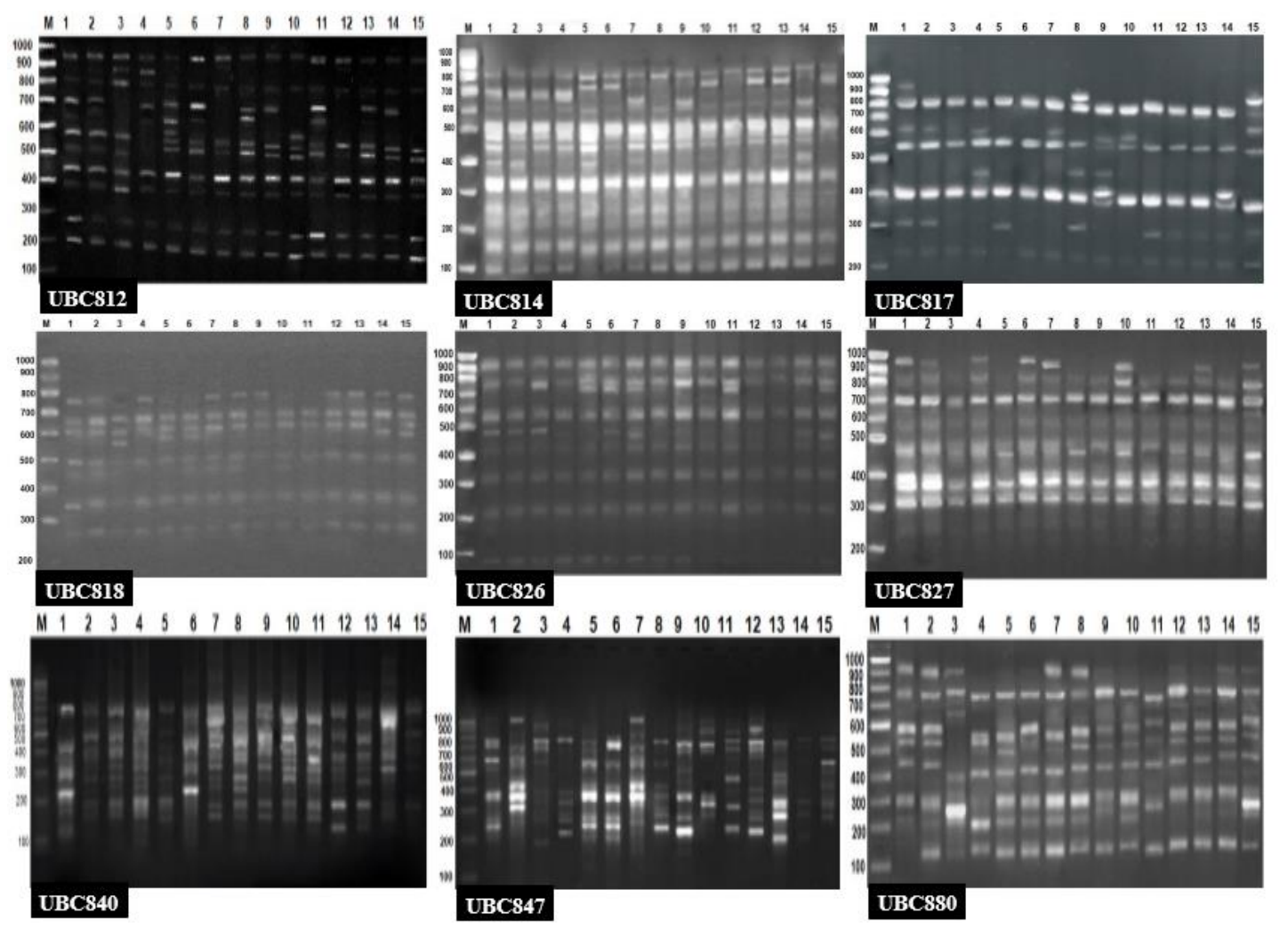

Fig 1. Images of DNA banding patterns for conducting reaction between genomes of the fifteen aphid species [A. gossypii $^{(\mathrm{L} 1)}, A$. citricola $^{(\mathrm{L} 2)}, A$. nerii $^{(\mathrm{L} 3)}, A$. rraccivora $^{(\mathrm{L} 4)}, H$. lactucae $^{(\mathrm{L} 5)}$, B. brassicae $^{(\mathrm{L} 6)}$, C. elaeagina $^{(\mathrm{L} 7)}, H$. pruni $^{(\mathrm{L} 8)}, P$.

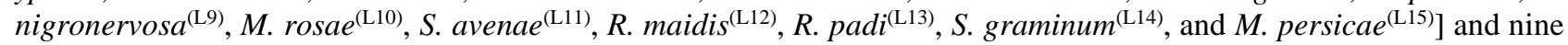
ISSRs primers 
banding patterns and yielded 145 fragments located between 200 and $950 \mathrm{bp}$, seven banding patterns were considered as polymorphic bands to achieve moderated polymorphism among the examined aphid species $(53.85 \%)$. The highest numbers of generated band patterns (12 bands) were observed in species Hyperomyzus lactucae and Brevicoryne brassicae, while the lowest ( 8 bands) were in species $C$. elaeagina and M. persicae. Absence of the fragment band with molecular size of $550 \mathrm{bp}$ characterized aphid species that belongs to the genus Aphis. Moreover, species A. craccivora could also be determined by absence of fragment band $530 \mathrm{bp}$.

Primer of UBC814 produced also 13 banding patterns situated between 100 and $820 \mathrm{bp}$ that most of observed bands (9 bands) were monomorphic thus low polymorphism (30.77\%) was detected. Generated banding patterns of species $B$. brassicae, $S$. avenae and $M$. persicae were the lowest (10 banding patterns) comparing with the other species. Despite polymorphism of UBC817 primer was moderated (63.64\%), it gave two unique bands with molecular sizes of 950 and $660 \mathrm{bp}$ that could characterize species A. gossypii and $M$. persicae, respectively. The lowest numbers of generating band patterns (4 bands) were observed in species $A$. nerii and $B$. brassicae.

ISSRs primer of UBC818 gave banding patterns situated in closest range (270 to $780 \mathrm{bp}$ ) that generated 97 fragments in 8 banding patterns with moderated level of polymorphism $(50 \%)$ among the tested aphid species. Species $S$. graminum could be determined by absence of the $610 \mathrm{bp}$ fragment band. Reaction of this primer with genomic DNA of $P$. nigronervosa yielded lowest number of band patterns (5 bands). The most observed DNA bands, generated by UBC826, were monomorphic bands thus it produced the lowest level of polymorphism (25\%) among the tested aphid species. Wherever, banding patterns with molecular sizes of 480 and $760 \mathrm{bp}$ were only considered as polymorphic bands.

The ISSRs primer of UBC827 generated 130 fragments of DNA with genomic DNA of the tested aphid species that was graded in eleven banding patterns in rang (250-950 bp). Although polymorphism of this primer was $36.36 \%$, the band pattern of $680 \mathrm{bp}$ was considered as speciesspecific band for species $M$. persicae. In addition, three polymorphic bands, with molecular sizes of
380, 460 and 950, were recognized. Each of Macrosiphum rosae and $M$. persicae had the highest numbers of banding patterns (10 bands).

UBC840 primer produced 90 polymorphic DNA fragments that graded in eleven banding patterns in rang (130-750 bp), to achieve high polymorphism level $(81.82 \%)$. Specimen of $M$. persicae characterized with absence of two fragments bands with molecular sizes of 180 and $430 \mathrm{bp}$, thus it had the least number of banding patterns (3 bands). Specimen of A. gossypii characterized also with absence one band of DNA fragment with molecular sizes of 500 $\mathrm{bp}$, which was common in other species.

UBC847 primer had widest banding pattern with molecular sizes ranging 200-1100 bp and the highest polymorphism (100\%) comparing with the other ISSRs primers, thus nearly 104 polymorphic fragment bands were detected. The DNA fragments of $790 \mathrm{bp}$ were considered as common banding pattern in the tested aphid species except A. citricola. Specimen of $S$. graminum had the lowest number of banding pattern (3 bands) followed by $R$. padi (4 bands).

UBC880 primer was also one of high polymorphic primers $(92.31 \%)$. It generated 122 fragments of DNA that phrased in 13 banding patterns with molecular sizes ranged from 140 to $940 \mathrm{bp}$. Species A. nerii could be identified by presence one species specific band in size of $660 \mathrm{bp}$. One common band with molecular size of 770 was detected. Absence of DNA fragment with molecular size of $140 \mathrm{bp}$ characterized A. gossypii, which was common in the other species. Moreover, each of A. gossypii, Aphis nerii and A. citricola characterized with absence of DNA fragment band with molecular size of $500 \mathrm{bp}$, while each of $A$. gossypii and A. citricola characterized with presence of DNA fragment with molecular size of $450 \mathrm{bp}$. Finally, aphid species of cereal hosts "S. avenae, $S$. graminum, $R$. padi and $R$. maidis" were characterized with absence of DNA fragment with molecular size of $220 \mathrm{bp}$.

Insect genetic diversity could be successfully conducted by using techniques of RAPD-PCR or ISSRs (Sartor et al 2008, Perumal et al 2009, Qiuet al 2009). In previous studies, Technique of RAPD-PCR could differentiate different aphid species "A. craccivora, A. fabae, A. gossypii, M. persicae, A. pisumand R. padi" (Cenis et al 1993), which belong to the same genus or different genera. In addition, this technique could successfully identify ten aphid species belong to genus Aphis (Amin et al 2008) and another 18 aphid species in Tribes Aphidini and Macrosiphini (Amin et al 2013) in Egypt. The arbitrary ten-mer primers gave DNA markers that could differentiate six 
aphid species "A. craccivora, A. faba, A. nerii, A. punicae, A. rumicis and A. zizyphi" in Genus Aphis. Furthermore, some aphid species "A. faba, A. nerii, A. rumicisand A. punicae" could be distinguished by one of the arbitrary primer (Chihadi 2006). Although each of B. brassicae, $C$. elaeagina and $H$. pruni could be distinguished by three DNA bands with primers C15, D2 and I17 in molecular sizes of 1282, 1132 and $1771 \mathrm{bp}$; B10, D5 and Z1 in molecular sizes of 900, 129 and $2250 \mathrm{bp}$; and primers D5, I17 and L20 in molecular sizes of 1401, 759 and 2084 bp, respectively, $P$. nigronervosa could be distinguished only by one DNA species - specific marker with primer B10 in molecular size of 830 bp. In contrary, no DNA species - specific bands was detected for $M$. rosae with those primers (Tabikha 2008).

Each of S. avenae and R. padi could be distinguished by DNA species-specific banding pattern (Lushai et al 1997), that could also be distinguished by another DNA species-specific markers with molecular sizes of 1555 and $225 \mathrm{bp}$ for primers I17 and Z1, respectively (Amin et al 2013). While other cereal aphid species could be distinguished by one DNA species - specific marker in molecular size of $237 \mathrm{bp}$ with primer L12 for $R$. maidis or two DNA species - specific markers in molecular sizes of 626 and 201 bp with primers I17 and UBC75, respectively for $S$. graminum (Tabikha 2008).

In ISSRs, occurrence primer-template mismatch is rare, and temperature of annealing is specified that rely on length of primers. Thus, it is considered as precise technique for detecting polymorphism (Wolff and Morgan-Richards 1998. In evolutionary, genetic, or ecological studies of biotypes, ISSRs technique save time and costs (Weng et al 2007). Thus, eleven species of cereal aphid were successively identified by five ISSRs primers that yielded 97 and 69 diagnostic markers. $R$. maidis could be distinguished by seven DNA markers that were as follow: 699 and $412 \mathrm{bp}$ by HP-09, 854 bp by HP-11, 398 bp by HP-12, 197 and 499 bp by HP-13 and 560 bp by HP-14, while DNA markers of $R$. padi were five (213 bp by HP-09, 716 bp by HP-11, 685 bp by HP-12, 322 bp by HP-13 and 600 bp by HP-14). In addition, each of $S$. graminum and $S$. avenae had higher DNA markers (8 bands) that DNA markers of $S$. graminum were 1109 bp by HP-09, 269 and 1301 bp by HP-11, 127 and 842 bp by HP-12, 507 and 585 bp by HP-13 and 49 bp by HP-14, while in case of $S$. avenae were 210 bp by HP-09, 605 bp by HP-11, 95, 271 and 460bp by HP-12, 993 bp by HP-13 and 223 and 500 bp by HP-14 (Helmi and Khafaga 2011).

Reaction of 6 arbitrary primers and 4 ISSRs primers with genomic DNA of 16 geographical specimens for $R$. padi revealed that those primers produced 416 polymorphic DNA fragments to achieve polymorphism $47.27 \%$ among the examined populations (Tabikha and Adss 2016). Although some banding patterns of UBC826 and UBC827 primers were polymorphic with the tested aphid species, they were monomorphic for most geographic populations of S. graminum in Egyptian agro-ecosystems (Tabikha and Adss 2021), which indicated that those primers are more convenient to determine different aphid species than geographical populations of specific species. While in current study, S. graminum could be determined by absence of the $610 \mathrm{bp}$ band that was generated by ISSRs primer of UBC818. In addition, $S$. graminum had lowest number of banding pattern ( 3 bands) followed by $R$. padi (4 bands) that was generated by UBC847 primer. Aphid species of cereal hosts "S. avenae, $S$. graminum, $R$. padi and $R$. maidis" were characterized with absence of DNA fragment with molecular size of $220 \mathrm{bp}$ that was generated by UBC880 primer.

\subsection{Molecular taxonomic keys}

The banding patterns of selected ISSRs primers (UBC812, UBC840, UBC818, UBC880 and UBC847), as presented in Table 3, that gave adequate level of polymorphism among the tested species were subjected to construct two alternative molecular branching taxonomic keys. Fourteen banding patterns with different molecular sizes, generated from reaction of primers UBC 880 and UBC847 with the genomic DNA of the tested aphid species, were subjected together to propose molecular taxonomic key as graphically illustrated in Fig 2. Another molecular taxonomic key was also suggested as shown in Fig $\mathbf{3}$ that was based on fifteen banding patterns with different molecular sizes generated from another three polymorphic primers such as UBC812, UBC840 and UBC818, consequently. The two suggested molecular taxonomic keys could successfully to discriminate the fifteen aphid species. Thus, discrimination procedure with the suggested molecular taxonomic keys may be precise, easy, simple, rapid, and inexpensive.

Molecular branching key can be constructed to identify numerous aphid species. Thus, Amin et al (2013) subjected 18 unique DNA marker to construct molecular branching key that differentiate 13 aphid species. Moreover, Tabikha and Adss (2021) proposed 
Table 3. Profile for polymorphic DNA bands of the fifteen aphid species, generated by the selected five ISSRs primers that were used in construction of the molecular taxonomic keys

\begin{tabular}{|c|c|c|c|c|c|c|c|c|c|c|c|c|c|c|c|c|}
\hline Primer & Mol. size & 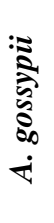 & 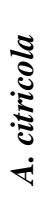 & 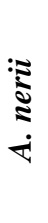 & 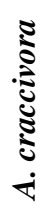 & 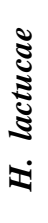 & 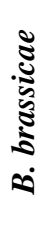 & 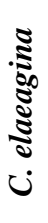 & 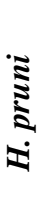 & 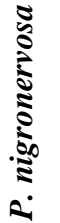 & 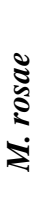 & 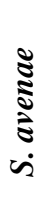 & 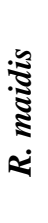 & ن & 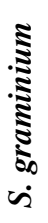 & 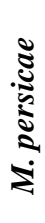 \\
\hline \multirow{7}{*}{ UBC812 } & 870 & 0 & 1 & 1 & 1 & 0 & 1 & 0 & 0 & 0 & 0 & 0 & 1 & 0 & 0 & 0 \\
\hline & 700 & 1 & 1 & 0 & 1 & 1 & 1 & 0 & 1 & 1 & 0 & 1 & 0 & 1 & 1 & 0 \\
\hline & 640 & 1 & 0 & 0 & 1 & 1 & 1 & 0 & 1 & 0 & 0 & 1 & 0 & 1 & 0 & 0 \\
\hline & 600 & 0 & 0 & 0 & 0 & 1 & 1 & 0 & 1 & 0 & 1 & 0 & 0 & 0 & 0 & 0 \\
\hline & 580 & 1 & 1 & 1 & 0 & 1 & 0 & 0 & 0 & 0 & 0 & 0 & 0 & 0 & 0 & 0 \\
\hline & 550 & 0 & 0 & 0 & 0 & 1 & 1 & 1 & 1 & 1 & 1 & 1 & 1 & 1 & 1 & 1 \\
\hline & 530 & 1 & 1 & 1 & 0 & 1 & 1 & 1 & 1 & 1 & 1 & 1 & 1 & 1 & 1 & 1 \\
\hline \multirow{4}{*}{ UBC818 } & 780 & 1 & 1 & 0 & 1 & 0 & 1 & 1 & 1 & 0 & 0 & 1 & 1 & 1 & 1 & 1 \\
\hline & 610 & 1 & 1 & 1 & 1 & 1 & 1 & 1 & 1 & 1 & 1 & 1 & 1 & 1 & 0 & 1 \\
\hline & 580 & 0 & 0 & 1 & 0 & 1 & 1 & 0 & 1 & 0 & 0 & 0 & 0 & 0 & 1 & 1 \\
\hline & 460 & 1 & 1 & 0 & 0 & 0 & 1 & 1 & 1 & 0 & 1 & 0 & 0 & 0 & 0 & 0 \\
\hline \multirow{9}{*}{ UBC 840} & 720 & 0 & 0 & 0 & 1 & 0 & 1 & 1 & 1 & 1 & 1 & 0 & 0 & 0 & 1 & 0 \\
\hline & 500 & 0 & 1 & 1 & 1 & 1 & 1 & 1 & 1 & 1 & 1 & 1 & 1 & 1 & 1 & 1 \\
\hline & 430 & 1 & 1 & 1 & 1 & 1 & 1 & 1 & 1 & 1 & 1 & 1 & 1 & 1 & 1 & 0 \\
\hline & 360 & 1 & 1 & 1 & 1 & 1 & 1 & 1 & 1 & 0 & 1 & 1 & 0 & 0 & 0 & 0 \\
\hline & 320 & 1 & 0 & 1 & 1 & 1 & 1 & 1 & 0 & 1 & 1 & 1 & 1 & 1 & 1 & 0 \\
\hline & 280 & 1 & 0 & 1 & 1 & 1 & 0 & 1 & 1 & 0 & 1 & 1 & 0 & 1 & 1 & 0 \\
\hline & 230 & 1 & 0 & 0 & 1 & 0 & 1 & 0 & 1 & 0 & 0 & 0 & 0 & 0 & 0 & 0 \\
\hline & 180 & 1 & 1 & 1 & 1 & 1 & 1 & 1 & 1 & 1 & 1 & 1 & 1 & 1 & 1 & 0 \\
\hline & 130 & 1 & 0 & 0 & 1 & 0 & 1 & 0 & 0 & 0 & 0 & 1 & 1 & 0 & 0 & 0 \\
\hline \multirow{13}{*}{ UBC847 } & 1100 & 1 & 1 & 0 & 0 & 0 & 0 & 1 & 0 & 1 & 0 & 0 & 1 & 0 & 0 & 0 \\
\hline & 900 & 0 & 0 & 1 & 0 & 1 & 0 & 1 & 0 & 1 & 1 & 1 & 1 & 1 & 0 & 0 \\
\hline & 790 & 1 & 0 & 1 & 1 & 1 & 1 & 1 & 1 & 1 & 1 & 1 & 1 & 1 & 1 & 1 \\
\hline & 650 & 1 & 1 & 1 & 0 & 1 & 1 & 1 & 0 & 0 & 1 & 1 & 0 & 0 & 0 & 1 \\
\hline & 600 & 1 & 1 & 1 & 0 & 1 & 1 & 1 & 1 & 0 & 0 & 0 & 0 & 0 & 0 & 1 \\
\hline & 520 & 1 & 1 & 0 & 0 & 0 & 0 & 0 & 1 & 0 & 0 & 0 & 1 & 0 & 0 & 1 \\
\hline & 420 & 0 & 1 & 0 & 1 & 1 & 1 & 1 & 1 & 0 & 1 & 0 & 0 & 0 & 0 & 0 \\
\hline & 380 & 1 & 1 & 0 & 1 & 1 & 1 & 1 & 1 & 1 & 0 & 1 & 1 & 1 & 1 & 1 \\
\hline & 320 & 0 & 1 & 1 & 1 & 1 & 1 & 0 & 1 & 0 & 1 & 1 & 1 & 0 & 0 & 0 \\
\hline & 280 & 1 & 1 & 1 & 1 & 1 & 1 & 1 & 1 & 1 & 1 & 1 & 0 & 1 & 1 & 0 \\
\hline & 250 & 1 & 0 & 0 & 0 & 1 & 1 & 0 & 1 & 1 & 0 & 1 & 1 & 0 & 0 & 0 \\
\hline & 220 & 0 & 0 & 0 & 1 & 1 & 1 & 0 & 0 & 0 & 0 & 1 & 0 & 0 & 0 & 0 \\
\hline & 200 & 0 & 0 & 1 & 0 & 0 & 1 & 0 & 0 & 0 & 0 & 0 & 0 & 0 & 0 & 0 \\
\hline \multirow{12}{*}{ UBC880 } & 940 & 1 & 1 & 1 & 0 & 0 & 0 & 1 & 1 & 0 & 0 & 0 & 1 & 0 & 1 & 1 \\
\hline & 660 & 0 & 0 & 1 & 0 & 0 & 0 & 0 & 0 & 0 & 0 & 0 & 0 & 0 & 0 & 0 \\
\hline & 600 & 1 & 1 & 0 & 0 & 0 & 1 & 0 & 1 & 1 & 1 & 1 & 1 & 1 & 1 & 1 \\
\hline & 580 & 1 & 1 & 0 & 1 & 1 & 1 & 1 & 1 & 0 & 0 & 0 & 1 & 1 & 1 & 1 \\
\hline & 550 & 1 & 1 & 0 & 1 & 1 & 1 & 0 & 1 & 0 & 0 & 0 & 1 & 1 & 1 & 1 \\
\hline & 500 & 0 & 0 & 0 & 1 & 1 & 1 & 1 & 1 & 1 & 1 & 1 & 1 & 1 & 1 & 1 \\
\hline & 450 & 1 & 1 & 0 & 0 & 0 & 0 & 0 & 0 & 0 & 0 & 0 & 0 & 0 & 0 & 0 \\
\hline & 390 & 0 & 0 & 1 & 1 & 1 & 1 & 1 & 1 & 1 & 1 & 1 & 1 & 1 & 1 & 1 \\
\hline & 300 & 1 & 1 & 0 & 0 & 1 & 1 & 1 & 1 & 1 & 1 & 0 & 1 & 1 & 1 & 1 \\
\hline & 260 & 0 & 0 & 1 & 0 & 0 & 0 & 0 & 0 & 0 & 0 & 1 & 0 & 0 & 0 & 0 \\
\hline & 220 & 1 & 1 & 1 & 1 & 1 & 1 & 1 & 1 & 1 & 1 & 0 & 0 & 0 & 0 & 1 \\
\hline & 140 & 0 & 1 & 1 & 1 & 1 & 1 & 1 & 1 & 1 & 1 & 1 & 1 & 1 & 1 & 1 \\
\hline
\end{tabular}




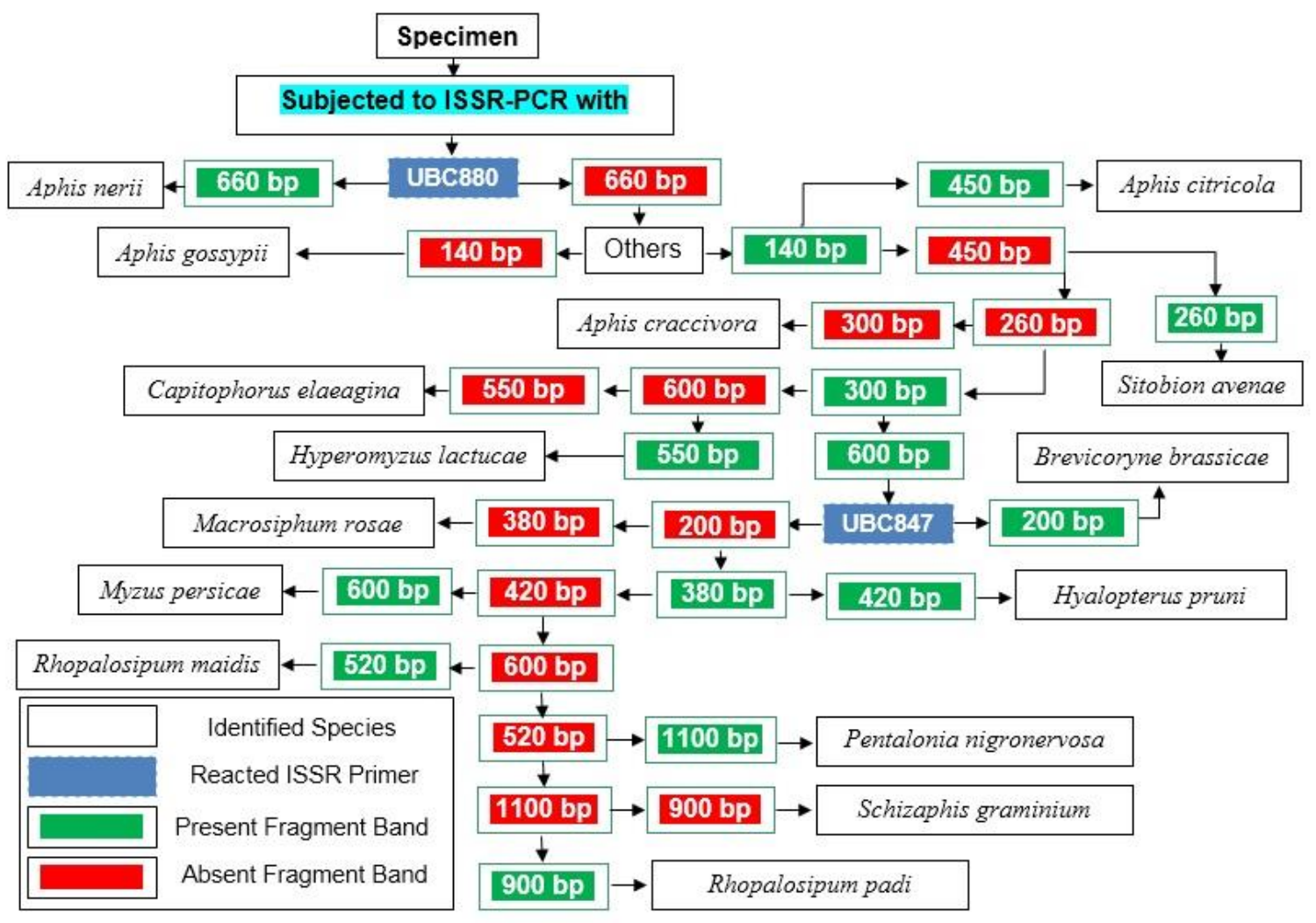

Fig 2. Proposed branching molecular key, based on generated DNA markers by two polymorphic ISSRs primers (USB847 and UBC880) to discriminate the fifteen aphid species

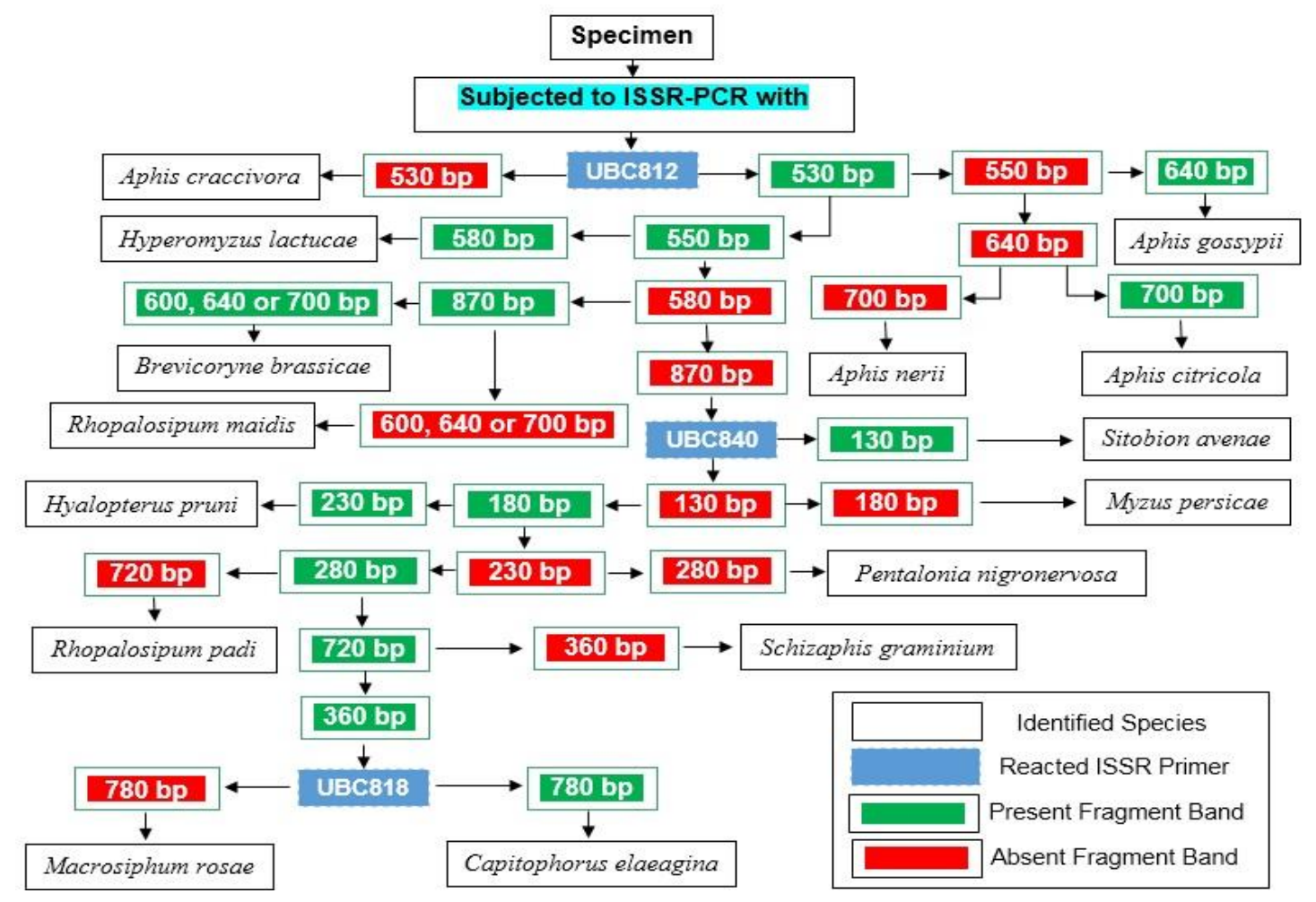

Fig 3. Proposed branching molecular key, based on generated DNA markers by three polymorphic ISSRs primers (USB812, USB818 and UBC840) to discriminate the fifteen aphid species 
a molecular branching key that based on six ISSRs primers (UBC-840, UBC-808, UBC-814, UBC-868, HB-12 and UBC-811) and 16 polymorphic DNA fragments with different molecular sizes, to discriminate 16 geographic populations of $S$. graminum that habitat Egyptian wheat fields.

\subsection{Phylogenetic relationships}

The similarity matrices of the fifteen examined aphid species, as shown in Table 4, reflected that the highest genetic homology (84.9\%) was observed between species $R$. padi and $S$. graminum. In additions, each of $A$. gossypii and A. citricola are genetically homologous species with similarity percentile $84.1 \%$. Despite, aphids' species of cereals host plants such as $S$. avenae, $R$. maidis, $R$. padi and $S$. graminum belong to different tribes, they are genetically homologous with similarity percentiles more than $80 \%$. In contrast, species $A$. craccivora and $M$. persicae are analogous genetically with low similarity percentile $(59.8 \%)$. High genetic divergence was observed also between $A$. nerii and M. persicae.

The generated phylogenetic tree from the fifteen different aphid species, shown in Fig 4, separated those species into two main clusters. The first cluster had A. nerii while the second one consisted of two sub-clusters. Where the first sub-cluster included $M$. persicae while two main groups appeared from the second subcluster. The first main group was for A. gossypii and A. citricola, while the second included two subgroups. The first sub-group was for A craccivora while the other sub-group consisted of two division. The first division included one clade for three aphid species belongs to Tribe Macrosiphini ( $P$. nigronervosa, M. rosae and C. elaeagina), while the second division consisted of two clades. Clades of second divisions were for cereal aphids' species "S. avenae, $S$. graminum, $R$. padi and $R$. maidis" and three other aphids species"H. lactucae, Hyalopteruspruni and $B$. brassicae".

Obtained results agree with Martinez et al (1997) who stated that each of Myzuspersicae and Aphis gossypii were analogous aphid species while Chihadi (2006) reported that each of A. citricolla and Aphis compositae were homologous aphid species based on RAPD-PCR with similarity percentile $88.6 \%$.

Genetic similarity indices of eleven cereal aphid species ranged from 73 to $98 \%$, that each of Anoecia corni and $H$. pruni were analogous species while each of $H$. pruni and Saltusaphis scirpus were homologous species. Thus aphid species "S. graminum, $R$. maidis, $R$. padi and Tetraneura africana" were placed in separated sub-cluster with similarity percentile of $84 \%$ (Helmi and Khafaga 2011). The results of proximity matrix analysis, based on DNA polymorphism for the eighteen aphid species, showed that $R$. maidis and $R$. padi are homologous species while each of $S$. graminum and Brachycaudus schwartzi are analogous species. Furthermore, the aphid species of cereal plants could also be placed in separated clade from the other species (Amin et al 2013).

Table 4. Similarity matrices of fifteen aphid species based on ISSRs banding patterns analysis

\begin{tabular}{|c|c|c|c|c|c|c|c|c|c|c|c|c|c|c|c|}
\hline & 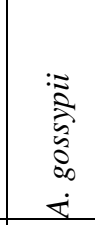 & $\begin{array}{l}-1 \\
0 \\
0 \\
0 \\
0 \\
0 \\
0 \\
0\end{array}$ & $\begin{array}{r}\vdots \\
\vdots \\
\vdots \\
\vdots \\
\vdots\end{array}$ & 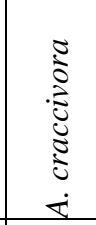 & 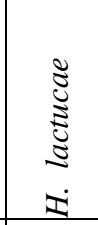 & 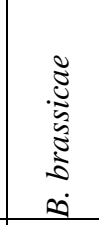 & $\begin{array}{l}\mathfrak{5} \\
: 0 \\
0 \\
0 \\
0 \\
0 \\
0 \\
ن\end{array}$ & $\begin{array}{l}\bar{\Sigma} \\
\vdots \\
\vdots \\
\vdots \\
\end{array}$ & $\begin{array}{l}\tilde{0} \\
0 \\
0 \\
\vdots \\
\vdots \\
0 \\
\vdots \\
\vdots \\
2\end{array}$ & 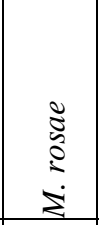 & 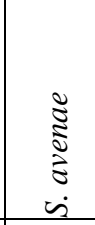 & 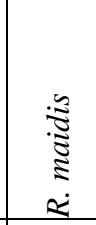 & $\begin{array}{l}\overrightarrow{\tilde{z}} \\
\mathbf{z} \\
\dot{z}\end{array}$ & 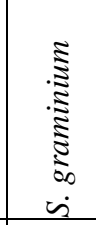 & 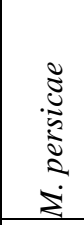 \\
\hline A. gossypii & 1.000 & & & & & & & & & & & & & & \\
\hline A. citricola & 0.841 & 1.000 & & & & & & & & & & & & & \\
\hline A. nerii & 0.644 & 0.687 & 1.000 & & & & & & & & & & & & \\
\hline A. craccivora & 0.701 & 0.706 & 0.671 & 1.000 & & & & & & & & & & & \\
\hline H. lactucae & 0.681 & 0.685 & 0.711 & 0.709 & 1.000 & & & & & & & & & & \\
\hline B. brassicae & 0.707 & 0.711 & 0.659 & 0.776 & 0.793 & 1.000 & & & & & & & & & \\
\hline C. elaeagina & 0.756 & 0.783 & 0.728 & 0.747 & 0.744 & 0.750 & 1.000 & & & & & & & & \\
\hline H. pruni & 0.742 & 0.747 & 0.636 & 0.733 & 0.812 & 0.795 & 0.747 & 1.000 & & & & & & & \\
\hline P. nigronervosa & 0.663 & 0.667 & 0.692 & 0.713 & 0.690 & 0.678 & 0.772 & 0.674 & 1.000 & & & & & & \\
\hline M. rosae & 0.644 & 0.686 & 0.691 & 0.732 & 0.771 & 0.736 & 0.813 & 0.753 & 0.756 & 1.000 & & & & & \\
\hline S. avenae & 0.678 & 0.644 & 0.709 & 0.750 & 0.790 & 0.753 & 0.723 & 0.729 & 0.731 & 0.728 & 1.000 & & & & \\
\hline R. maidis & 0.686 & 0.711 & 0.654 & 0.695 & 0.714 & 0.721 & 0.711 & 0.738 & 0.740 & 0.695 & 0.779 & 1.000 & & & \\
\hline R. padi & 0.714 & 0.699 & 0.642 & 0.747 & 0.788 & 0.729 & 0.763 & 0.768 & 0.750 & 0.769 & 0.813 & 0.824 & 1.000 & & \\
\hline S. graminium & 0.686 & 0.690 & 0.654 & 0.695 & 0.735 & 0.701 & 0.753 & 0.802 & 0.763 & 0.716 & 0.734 & 0.766 & 0.849 & 1.000 & \\
\hline M. persicae & 0.648 & 0.690 & 0.614 & 0.598 & 0.674 & 0.721 & 0.711 & 0.718 & 0.634 & 0.635 & 0.651 & 0.744 & 0.731 & 0.722 & 1.000 \\
\hline
\end{tabular}




\section{Arab Univ J Agric Sci (2021) 29 (3) 873-886}

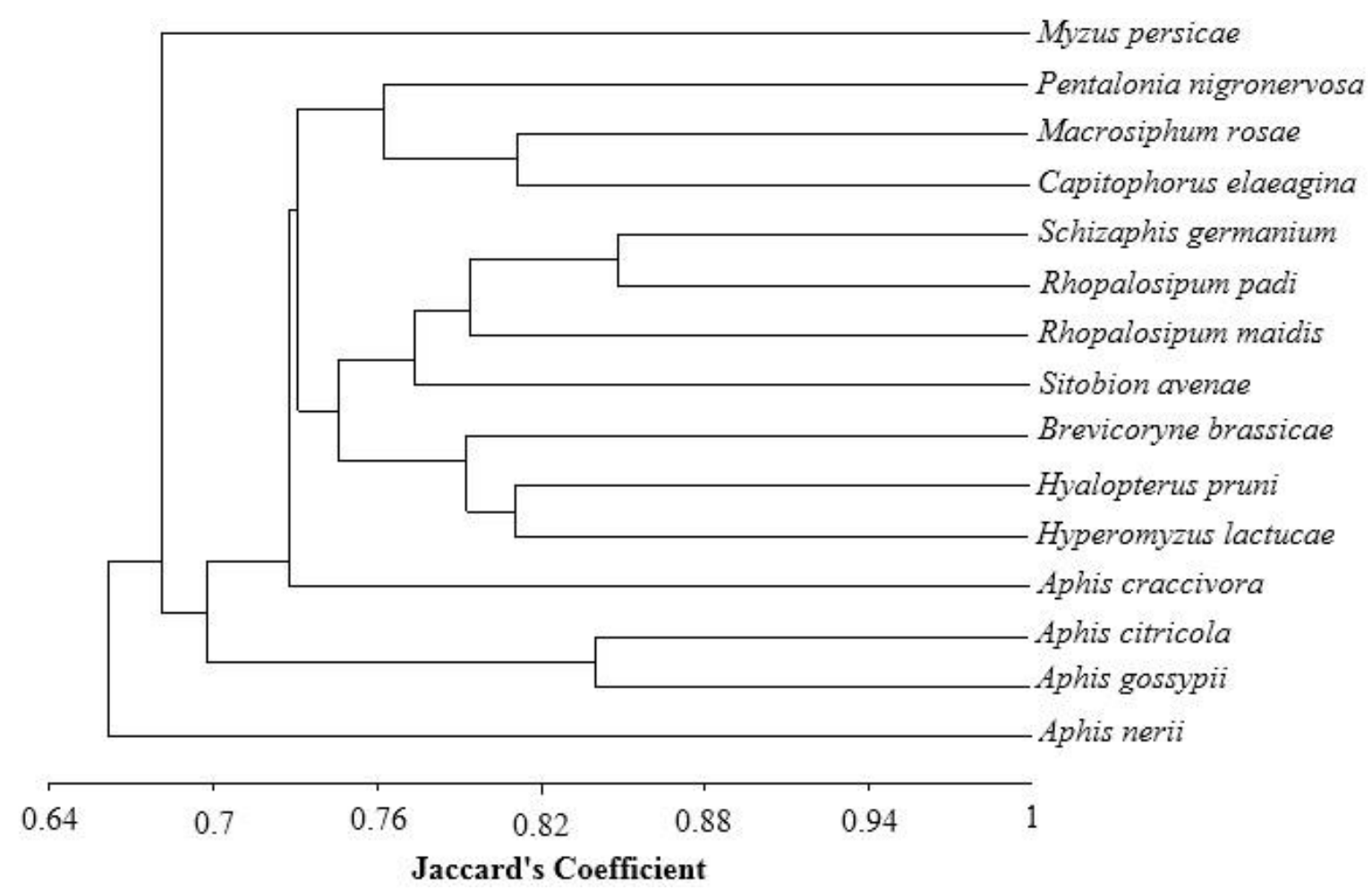

Fig 4. Dendrogram for studying phylogeny of the fifteen aphid species based on analysis of ISSRs similarity matrices

\section{Conclusion}

The Tested ISSRs succeeded to generate many polymorphic DNA fragments bands with wide range of molecular sizes, four of them were species-specific markers for three aphid species. The other polymorphic banding patterns were subjected successfully to construct two alternative molecular taxonomic key that discriminate the fifteen aphid species. The phylogenetic relationship among some aphid species confirmed that each of $R$. padi and $S$. graminum in addition each of $A$. gossypii and A. citricola are genetically homologous species, while A. craccivora and M. persicae are analogous genetically species. Although the tested aphid species of cereals host plants belong to different tribes, they are genetically homologous with similarity percentiles more than $80 \%$.

\section{References}

Abbot P (2001) Individual and population variation in invertebrates revealed by Inter-simple Sequence Repeats (ISSRs). Journal of Insect Science, 1, 8. DOI:10.1093/jis/1.1.8
Amin AH, Draz KA, Soliman, KA, Tabikha, RM (2013) Genetic fingerprints and phylogenetic relationships of eighteen aphid species from Egypt (Hemiptera: Sternorrhyncha: Aphididae). Munis Entomology and Zoology, 8, 387-406.

Amin AH, Shahadi-Fatima H, Soliman KA (2008) Genetic fingerprints and phylogenetic relationships of ten Aphis species found in Egypt (Hemiptera : Aphididae). Journal of Chemical and Environmental Sciences, 3, 631-647.

Armstrong KF, Ball SL (2005) DNA barcodes for biosecurity: invasive species identification. Philosophical Transactions of the Royal Society of London. Series B, Biological Sciences, 360, 1813-1823.

DOI:10.1098/rstb.2005.1713

Blackman RL, Eastop VF (1994) Aphids on the World's Trees: An Identification and Information Guide. CAB International, Wallingford.

DOI: https://doi.org/10.1017/S0007485300034465

Blackman RL, Eastop VF (2000) Aphids on the World's Crops: An Identification and Information Guide, second ed. John Wiley \& Sons, Chichester. 
Holman J (2008) Blackman RL \& Eastop VF: Aphids on the world's herbaceous plants and shrubs. European Journal of Entomology 105,164-164. Doi:10.14411/Eje.2008.024

Brault V, Tanguy S, Reinbold C, Le Trionnaire G, Arneodo J, Jaubert-Possamai S, Guernec G, Tagu D (2010) Transcriptomic analysis of intestinal genes following acquisition of pea enation mosaic virus by the pea aphid $A$ cyrthosiphonpisum. Journal of General Virology, 91, 802-808. DOI:10.1099/vir.0.012856-0

Capinera JL (2002) North American vegetable pests: the pattern of invasion. American Entomologist, 48, 20-39. DOI:10.1093/ae/48.1.20

Carew ME, Pettigrove V, Hoffmann AA (2003) Identifying chironomids (Diptera: Chironomidae) for biological monitoring with PCR-RFLP. Bulletin of Entomological Research, 93, 483-490.

DOI:10.1079/ber2003268

Carew ME, Pettigrove V, Hoffmann AA (2005) The utility of DNA markers in classical taxonomy: Cytochrome Oxidase I markers to differentiate Australian Cladopelma (Diptera: Chironomidae) midges. Annals of the Entomological Society of America, 98, 587-594.

DOI:10.1603/0013-

\section{6(2005)098[0587:TUODMI]2.0.CO;2}

Cenis JL, Perez P, Fereres A (1993) Identification of Aphid (Homoptera: Aphididae) species and clones by Random Amplified Polymorphic DNA. Annals of The Entomological Society of America, 86, 545-550. DOI:10.1093/aesa/86.5.545

Chihadi FH (2006) Taxonomical studies on aphids by using modern techniques. Ph.D. in Economic Entomology, Plant protection Department, Faculty of Agriculture, Ain Shams University, Egypt. 83pp.

Coeur d'acier A, Cruaud A, Artige E, Genson G, Clamens AL, Pierre E, Hudaverdian S, Simon JC, Jousselin E, Rasplus JY (2014) DNA barcoding and the associated PhylAphidB@se website for the identification of European aphids (Hemiptera: Aphididae). PLoS ONE, 9, e97620.

DOI:10.1371/journal.pone.0097620

Emden HFV, Harrington R (2007) Aphids as Crop Pests. CAB International, Oxford, UK.

Gui FR, Wan FH, Guo JY (2008) Population genetics of Ageratinaadenophorausing inter-simple sequence repeat (ISSR) molecular markers in China. Plant Biosystems, 142, 255-263.

DOI:10.1080/112635-00802150399

Guo J, Wang Z, Francis F (2017) Use of molecular markers for entomological diversity assessment and their application in population study of aphids. Faunistic Entomology, 70.

DOI:10.25518/2030-6318.3647

Habib A, El-kady E (1961) The Aphididae of Egypt. Bulletin of The Entomological Society of Egypt, 45, 1137.

Hebert PDN, Penton EH, Burns JM, Janzen DH, Hallwachs W (2004) Ten species in one: DNA barcoding reveals cryptic species in the Neotropical skipper butterfly Astraptesfulgerator. Proceedings of the National Academy of Sciences of the United States of America, 101, 14812-14817.

DOI:10.1073/pnas.0406166101

Helmi A, Khafaga AF (2011) Molecular fingerprinting of certain cereal aphids in Egypt (Hemiptera: Sternorrhyncha: Aphididae) using RAPD and ISSR markers. Journal of Entomology, 8, 327-340.

DOI:10.3923/je.2011.327.340

Helmi A, Sharaf AA, Ibrahim HE (2016) Fingerprinting of leafhoppers on medicinal and aromatic plants in Egypt using ISSRs. Journal of Plant Protectionand Pathology, Mansoura University, 7, 751-756.

DOI:10.21608/jppp.2016.52137

Kim H, Lee S, Jang Y (2011) Macroevolutionary patterns in the Aphidini aphids (Hemiptera: Aphididae): diversification, host association, and biogeographic origins. PloS ONE, 6, e24749.

DOI:10.1371/journal.pone.0024749

Kinyanjui G, Khamis FM, Mohamed S, Ombura LO, Warigia M, Ekesi S (2016) Identification of aphid (Hemiptera: Aphididae) species of economic importance in Kenya using DNA barcodes and PCRRFLP-based approach. Bulletin of Entomological Research, 106, 63-72. DOI:10.1017/S0007-485315000796 Lee W, Kim H, Lim J, Choi HR, Kim Y, Kim YS, Ji JY, Foottit RG, Lee S (2011) Barcoding aphids (Hemiptera: Aphididae) of the Korean Peninsula: updating the global data set. Molecular Ecology Resources, 11, 32-37. DOI:10.1111/j.1755-0998.2010.02877.x

Liu J, Gui F, Li Z (2010) Genetic diversity of the planthopper, Sogatella furcifera in the Greater Mekong Subregion detected by inter-simple sequence repeats (ISSR) markers. Journal of Insect Science, 10, 52. DOI:10.1673/031.010.5201 
Lozier JD, Foottit RG, Miller GL, Mills NJ, Roderick GK (2008) Molecular and morphological evaluation of the aphid genus Hyalopterus Koch (Insecta: Hemiptera: Aphididae), with a description of a new species. Zootaxa, 1688, 1-19.

DOI:10.5281/zenodo.180576

Lushai G, Loxdale HD, Brookes CP, venMende N, Harrington R, Herdie J (1997) Genotypic variation among different phenotypes within aphid clones. Proceedings of the Royal Society B: Biological Sciences, 264, 725-730.

DOI:10.1098/rspb.1997.0103

Martinez TD, Moya A, Hebert PDN, Simon JC (1997) Geographic distribution and seasonal variation of mitochondrial DNA haplotypes in the aphid Rhopalosiphum padi (Hemiptera: Aphididae). Bulletin of Entomological Research, 87, 161-167. DOI:10.1017/S0007485300027309

McNeely JA, Mooney HA, Neville LE, Schei P, Waage JK (2001) A Global Strategy on Invasive Alien Species. IUCN in collaboration with the Global Invasive Species Programme, Gland, Switzerland and Cambridge, UK.

Miller GL, Foottit RG (2009) The taxonomy of crop pests: the aphids. pp. 463-473. In: Foottit, RG, Adler PH (Eds) Insect Biodiversity: Science and Society. Oxford, Wiley-Blackwell.

Mullis KB, Faloona FA (1987) Specific synthesis of DNA in vitro via a polvmerase catalyzed chain reaction. Mertnis in Enzymology, 155, 335-350.

DOI:10.1016/0076-6879(87)55023-6

Perumal Y, Marimuthu M, Salim AP, Ponnusamy B (2009) Host plant mediated population variations of cotton whitefly Bemisiatabaci (Gennadius) (Aleyrodidae: Homoptera) characterized with random DNA markers. American Journal of Biochemistry and Biotechnology, 5, 40-46.

DOI:10.3844/ajbbsp.2009.40.46

Qiu B, Chen Y, Peng LLW, Li X, Ahmed MZ, Mathur V, Duandand Y, Ren S (2009) Identification of three major Bemisia tabaci biotypes in China based on morphological and DNA polymorphisms. Progress in Natural Science, 19, 713718. DOI:10.1016/j.pnsc.2008.08.013

Raina SN, Rani V, Kojima T, Ogihara Y, Singh KP, Devaru-math RM (2001) RAPD and ISSR fingerprints as useful genetic markers for analysis of genetic diversity. In: Liu et al. varietal identification, and phylogenetic relationships in peanut
(Arachis hypogaea) cultivars and wild species. Genome, 44, 763-772. PMID: 11681599.

DOI: $10.1139 / \mathrm{g} 01-064$

Sartor C, Demichelis S, Cenis JL, Coulibaly AK, Bosco D (2008) Genetic variability of Bemisia tabaciin the Mediterranean and Sahel Regions. Bulletin of Insectology, 61, 161-162.

Sneath PHA, Sokal RR (1973) Numerical Taxonomy The Principles and Practice of Numerical Classification. WH Freeman, San Francisco.

Tabikha RM (2008) Taxonomical studies on some aphid species by using modern techniques. Ph.D. in Economic Entomology, Plant Protection Department, Faculty of Agriculture, Alexandria University, Damanhour Branch.

Tabikha RM, Adss IA (2016) Genetic and morphological variations among geographical populations of Rhopalosiphum padi (L.) (Hemiptera: Aphididae) in Egypt, using RAPD and ISSR markers. Munis Entomology and Zoology, 11, 695-708.

Tabikha RM, Adss IA (2021) Morphologic and genetic analysis for geographic populations of greenbug Schizaphis graminum (Hemiptera : Aphididae) in Egypt . Biologia, 76, 77-89.

DOI: $10.2478 / \mathrm{s} 11756-020-00501-2$

Valenzuela I, Eastop VF, Ridland PM, Weeks AR (2009) Molecular and morphometric data indicate a new species of the aphid Genus Rhopalosiphum (Hemiptera: Aphididae). Annals of the Entomological Society of America, 102, 914-924.

DOI:10.1603/008.102.0602

Valenzuela I, Hoffmann AA, Malipatil MB, Ridland PM, Weeks AR (2007) Identification of aphid species (Hemiptera: Aphididae: Aphidinae) using a rapid polymerase chain reaction restriction fragment length polymorphism method based on the cytochrome oxidase subunit I gene. Australian Journal of Entomology, 46, 305-312.

von Dohlen CD (2009) Aphid molecular systematics: history, progress and prospects. Redia, 92, 39-45.

von Dohlen CD, Rowe CA, Heie OE (2006) A test of morphological hypotheses for tribal and subtribal relationships of Aphidinae (Insecta: Hemiptera: Aphididae) using DNA sequences. Molecular Phylogenetics and Evolution, 38, 316-329.

DOI:10.1016/j.ympev.2005.04.035

Weng Y, Azhaguvel P, Michels GJ, Rudd JC (2007) Cross-species transferability of microsatellite markers from six aphid (Hemiptera: Aphididae) species and 
Arab Univ J Agric Sci (2021) 29 (3) 873-886

their use for evaluating biotypic diversity in two cereal aphids. Insect Molecular Biology, 16, 613622. DOI:10.1111/j.1365-2583.2007.00757.x

Williams JGK, Kubelik AR, Livak KJ, Rafalski JA, Tingey SV. (1990) DNA polymorphism amplified by arbitrary primers are useful genetic markers. Nucleic Acid Research, 18, 6531- 6533.

DOI:10.1093/nar/18.22.6531
Wolff K, Morgan-Richards M (1998) PCR markers distinguish Plantago major subspecies. Theoretical and App;ied Genetics, 96, 282-286.

Worf GL, Heimann MF, Pellitteri PJ (1995) Sooty Mold. pp. 2. University of Wisconsin Cooperative Extension Publication. Madison Wisconsin A2637. 